\title{
Experiências Místicas no Uso de Diversos Psicodélicos: Análise de um Survey Online
}

\section{Luna M. Ursini*, Marcelo Falchi, Natalia Mota, Sidarta Ribeiro, Luís Fernando Tófoli}

\section{Resumo}

Introdução: Experiências místicas associadas ao uso de psicodélicos têm sido associadas a desfechos positivos de saúde mental em estudos anteriores. Objetivo: Este estudo tem como objetivo investigar os determinantes de experiências místicas induzidas por psicodélicos em um questionário online. Método: Em uma amostra de 1507 respostas analisouse a associação uni e multivariada entre escores das quatro dimensões da escala de experiências místicas MEQ30 com as demais variáveis coletadas. Resultados: $\mathrm{Na}$ análise multivariada, houve associações significativas com as pontuações mais altas nas dimensões da MEQ30, com destaque para a associação do uso de cogumelos psicodélicos/psilocibina com o escores mais altos em todas as dimensões. Os resultados apontam na direção de que os diferentes psicodélicos podem apresentar resultados diversos nas dimensões da MEQ30 e que o uso de cogumelos psicodélicos/psilocibina se mostrou independentemente associado com maiores escores em todas as dimensões da escala.

Palavras-chave: zsicodélicos, experiências místicas, escalas psicométricas

\section{Introdução}

Pesquisas recentes têm reacendido o interesse pelas substâncias psicodélicas e sua aplicação na pesquisa e na terapêutica de transtornos mentais. Um importante componente da fenomenologia psicodélica são as experiências místicas, que têm sido associadas em alguns estudos a desfechos positivos. A principal ferramenta psicométrica utilizada para avaliar experiências místicas é denominada Mystical Experience Questionnaire (MEQ30), que já foi traduzida e validada para o português brasileiro ${ }^{1}$ e é composta por quatro dimensões: experiências místicas; humor positivo; transcendência de tempo e espaço; e inefabilidade. Apesar de sua importância, ainda não se conhece com clareza quais variáveis estão associadas com as respostas a cada uma destas dimensões. Este estudo tem como objetivo avaliar a associação entre as dimensões de uma escala de experiências místicas com o uso de diversas drogas psicodélicas, determinantes individuais ("set"), variáveis do contexto de uso ("setting").

\section{Resultados e Discussão}

Este estudo utilizou a amostra de 1507 indivíduos que responderam o questionário online usado para a validação da versão brasileira do Questionário de Experiências Místicas (MEQ30) ${ }^{1}$. A partir dos escores contínuos de cada dimensão da escala foram criadas quatro variáveis dicotômicas dividindo os sujeitos entre os que tiveram respostas nulas a leves e os que tiveram respostas de moderadas a extremas. A associação univariada dos escores dicotomizados foi testada com variáveis relacionadas ao indivíduo, às substâncias psicodélicas utilizadas e aos contextos de uso. Todas as associações univariadas com $p<=0,25$ foram incluídas no modelo multivariado de regressão logística.

$\mathrm{Na}$ análise multivariada da amostra completa houve associações significativas e independentes com os escores mais altos das dimensões da MEQ30, incluindo substâncias utilizadas, dados pessoais e informações de contexto. Relatamos a seguir as associações significativas.

No caso dos dados individuais, o gênero feminino se mostrou associado com a presença de escores mais altos de experiências místicas e humor positivo. A idade apresentou uma associação inversa com as respostas mais altas em transcendência de tempo e espaço e em inefabilidade. Não ter ensino superior completo mostrou associação aumentada com maiores medidas de experiências místicas e humor positivo.

Todas as dimensões da escala mostraram influências significativas de quais substâncias foram utilizadas. Houve associação do uso de cogumelos psicodélicos/psilocibina com escores altos em todas as dimensões (o uso de MDMA foi a resposta de contraste), sendo que na maioria dos casos a associação com maiores razões de chance nos modelos multivariados (com exceção da dimensão de transcendência de tempo e espaço). Por outro lado, o uso de MDMA se mostrou consistentemente associado a respostas mais baixas em todas as dimensões da MEQ30. Ter usado ayahuasca, LSD ou outras substâncias psicodélicas também esteve associado com respostas mais altas a todas as dimensões, menos a de humor positivo.

No caso das variáveis de contexto, houve uma associação com escores mais altos nas dimensões de transcendência de tempo e espaço e de inefabilidade com o tempo decorrido desde a experiência: quanto mais distante foi a experiência no tempo, maior a chance de escore mais alto. Ter feito uso ritual de psicodélico se mostrou associado com chances mais altas de estar no grupo de respostas mais elevadas de inefabilidade.

\section{Conclusões}

Os resultados apontam na direção de que psicodélicos diferentes podem apresentar resultados diversos nas dimensões da MEQ30, com um destaque na resposta ao uso de psilocibina/cogumelos psicodélicos e que variáveis pessoais como sexo, idade e escolaridade, ou contextuais como uso ritual ou tempo desde o uso podem influenciar tais dimensões.

\section{Agradecimentos}

Agradecemos ao Programa Institucional de Bolsas de Iniciação Científica (PIBIC) da UNICAMP e ao CNPq.

${ }^{1}$ Schenberg, E.E.; Tófoli, L. F.; Rezinovsky, D.; et al. Translation and cultural adaptation of the States of Consciousness Questionnaire (SOCQ) and statistical validation of the Mystical Experience Questionnaire (MEQ30) in Brazilian Portuguese. Archives of Clinical Psychiatry. 2017, 44(1), 1-5. 